\title{
Myelomeningocele-associated hydrocephalus: nationwide analysis and systematic review
}

\author{
David J. McCarthy, MSc, Dallas L. Sheinberg, MSc, Evan Luther, MD, and \\ Heather J. McCrea, MD, PhD
}

Department of Neurological Surgery, University of Miami Miller School of Medicine, Miami, Florida

\begin{abstract}
OBJECTIVE Myelomeningocele (MMC), the most severe form of spina bifida, is characterized by protrusion of the meninges and spinal cord through a defect in the vertebral arches. The management and prevention of MMC-associated hydrocephalus has evolved since its initial introduction with regard to treatment of MMC defect, MMC-associated hydrocephalus treatment modality, and timing of hydrocephalus treatment.
\end{abstract}

METHODS The Nationwide Inpatient Sample (NIS) database from the years 1998-2014 was reviewed and neonates with spina bifida and hydrocephalus status were identified. Timing of hydrocephalus treatment, delayed treatment (DT) versus simultaneous MMC repair with hydrocephalus treatment (ST), and treatment modality (ETV vs ventriculoperitoneal shunt [VPS]) were analyzed. Yearly trends were assessed with univariable logarithmic regression. Multivariable logistic regression identified correlates of inpatient shunt failure. A PRISMA systematic literature review was conducted that analyzed data from studies that investigated 1) MMC closure technique and hydrocephalus rate, 2) hydrocephalus treatment modality, and 3) timing of hydrocephalus treatment.

RESULTS A weighted total of 10,627 inpatient MMC repairs were documented in the NIS, 8233 (77.5\%) of which had documented hydrocephalus: 5876 (71.4\%) were treated with VPS, 331 (4.0\%) were treated with ETV, and $2026(24.6 \%)$ remained untreated on initial inpatient stay. Treatment modality rates were stable over time; however, hydrocephalic patients in later years were less likely to receive hydrocephalus treatment during initial inpatient stay (odds ratio [OR] 0.974, $p=0.0331$ ). The inpatient hydrocephalus treatment failure rate was higher for patients who received ETV treatment (17.5\% ETV failure rate vs $7.9 \%$ VPS failure rate; $p=0.0028$ ). Delayed hydrocephalus treatment was more prevalent in the later time period $(77.9 \%$ vs $69.5 \%, p=0.0287)$. Predictors of inpatient shunt failure included length of stay, shunt infection, jaundice, and delayed treatment. A longer time between operations increased the likelihood of inpatient shunt failure (OR 1.10, $p$ < 0.0001). However, a meta-analysis of hydrocephalus timing studies revealed no difference between ST and DT with respect to shunt failure or infection rates.

CONCLUSIONS From 1998 to 2014, hydrocephalus treatment has become more delayed and the number of hydrocephalic MMC patients not treated on initial inpatient stay has increased. Meta-analysis demonstrated that shunt malfunction and infection rates do not differ between delayed and simultaneous hydrocephalus treatment.

https://thejns.org/doi/abs/10.3171/2019.7.FOCUS19469

KEYWORDS myelomeningocele; spina bifida; hydrocephalus; cerebrospinal fluid shunting

$\mathrm{M}$ YELOMENINGOCELE (MMC) is the most severe form of spina bifida, characterized by protrusion of the meninges and spinal cord through a defect in the vertebral arches. The incidence of MMC ranges between 0.2 and 2 per 1000 live births, resulting in a spectrum of devastating clinical manifestations, including Chiari II malformation, genitourinary dysfunction, sensory and motor defects, and hydrocephalus. ${ }^{23,52}$ While all patients with MMC have ventriculomegaly, not all require treatment for hydrocephalus. The reported incidence of MMC-related hydrocephalus following postnatal closure of the MMC defect ranges from $57 \%$ to $86 \%$. $^{6,8,14,19,26,37,48,59 \text {, }}$ 63,65 The management of MMC-associated hydrocephalus has evolved since its initial introduction in the early 1950s. While a CSF shunt was initially the only treatment, some patients are now treated with endoscopic third ventriculostomy (ETV) or a combination of ETV and choroid plexus cauterization (ETV/CPC). Additionally, some patients are

ABBREVIATIONS CPC = choroid plexus cauterization; DT = delayed treatment; $\mathrm{ETV}=$ endoscopic third ventriculostomy; $\mathrm{MMC}=$ myelomeningocele; MOMS = Management of MMC Study; NIS = Nationwide Inpatient Sample; PRISMA = Preferred Reporting Items for Systematic Reviews and Meta-Analyses; ST = simultaneous treatment; VPS = ventriculoperitoneal shunt.

SUBMITTED June 1, 2019. ACCEPTED July 25, 2019.

INCLUDE WHEN CITING DOI: 10.3171/2019.7.FOCUS19469. 
treated for hydrocephalus at the same time as initial closure, while others are followed after closure to determine whether they will require intervention for hydrocephalus.

The pathophysiology of MMC-associated hydrocephalus is not fully elucidated; however, one theory is that inappropriate in-utero CSF outflow through the MMC defect leads to underdevelopment of normal CSF drainage pathways. ${ }^{32}$ These theories laid the scientific foundation for the initial animal studies and pilot human studies that evaluated prenatal MMC closure, with the hope that earlier closure of the defect would result in milder neurological deficits and less postnatal hydrocephalus. . $^{16,17,33,34,56}$

Ultimately, these studies were the foundation for the Management of MMC Study (MOMS). Published in 2011, MOMS compared prenatal intrauterine MMC closure to traditional postnatal repair and demonstrated that hydrocephalus rates in prenatal MMC repair were favorable to those of postnatal closure. ${ }^{1}$ A critique of this MOMS trial conclusion was that CSF diversion practices may have evolved over the trial period and since, with the thought that the threshold for treating hydrocephalus has increased and more patients are treated with ETV with or without CPC.

We hoped to elucidate shifts in MMC hydrocephalus management with a nationwide database. We review the Nationwide Inpatient Sample (NIS) from 1998 to 2014 for MMC patients, reporting the incidence and postnatal management of MMC-associated hydrocephalus. Additionally, we conduct a systematic review of the literature identifying studies that investigate MMC closure technique and hydrocephalus rate, MMC hydrocephalus treatment modality, and timing of hydrocephalus treatment.

\section{Methods \\ NIS Review}

The NIS from the years 1998-2014 was reviewed. Details regarding the NIS can be found on http://hcupnet. ahrq.gov. Patients less than 28 days old with spina bifida (ICD-9 code 741.xx) and repair of spinal meningocele procedure (ICD-9 codes 035.1, 035.9) were identified. Patients were separated by hydrocephalus status (ICD-9 codes 741.9x, 741.0x). Patients with ICD-9 codes of spina bifida without hydrocephalus and concomitant codes of hydrocephalus (ICD-9 331.3, 331.4) or hydrocephalus treatment (ventriculoperitoneal shunt [VPS] ICD-9 02.3x; ETV ICD-9 0.22, 0.222) were considered to have hydrocephalus. Shunt infection was defined as ICD-9 codes 996.63 or 996.60. Additional ICD-9 coding was utilized to identify common neonatal disease processes such as respiratory distress syndrome, wound infection, hematological disorders, necrotizing enterocolitis, bradycardia, tachycardia, jaundice, and electrolyte abnormalities.

\section{NIS Statistics}

For the years 1998-2011 and 2012-2014 the adjusted NIS weights "TRENDWT" and "DISCWT" were utilized, respectively, to adjust for temporal database changes. Categorical variables were presented as estimated weighted frequency and either row or column percentiles. Statistical analyses of categorical variables were performed us- ing chi-square and Fisher's exact tests, as appropriate. The normality of continuous variables was assessed graphically and statistically, with nonparametric distributions represented as medians and interquartile ranges (IQRs), whereas normal distributions were represented as weighted mean estimates. Comparisons of means of parametric variables were performed using least-squared means analysis, while nonparametric distributions were compared using the Wilcoxon rank-sum test adjusting for clustering and stratification. ${ }^{38}$

Time trend series plots were created for treatment modality and time of treatment for hydrocephalus. Patient records with procedure date available for both MMC repair and hydrocephalus treatment procedures were analyzed to assess timing of hydrocephalus treatment and MMC repair with simultaneous hydrocephalus treatment (ST) versus delayed hydrocephalus treatment (DT), defined as hydrocephalus treatment on a different day than initial closure. To assess for significant shifts in MMC hydrocephalus management, the earlier period was defined as the years 1998-2006 and the later period as 2007-2014. Yearly trends were assessed with univariable logarithmic regression with year treated as a continuous variable. Furthermore, records with time of treatment available were assessed with a univariable and multivariable logistic regression to identify correlates of inpatient shunt failure, defined as documented return to the operating room. Correlates with a significance level of $p<0.2$ were included in the multivariable regression. A backward elimination multivariable model was utilized and only covariates with $\mathrm{p}$ values $<0.1$ remained in the final model. A p value $\leq$ 0.05 was considered statistically significant. The statistical software program SAS (version 9.4; SAS Institute) was used for analysis.

\section{Systematic Review}

We conducted a systematic literature review in accordance with Preferred Reporting Items for Systematic Reviews and Meta-Analyses (PRISMA) guidelines that analyzed data from studies reporting the treatment of hydrocephalus in newborns with MMC. ${ }^{27}$ Using the PubMed database, we searched for articles published from January 1970 through June 2019 utilizing the terms ("cerebrospinal fluid shunts," OR "hydrocephalus") AND ("myelomeningocele"). The Rayyann systematic review app was utilized by 2 authors, who separately reviewed the search articles. ${ }^{43}$ Additional papers were found through reference lists from pertinent articles. Full-text English cohort studies published in peer-reviewed journals were selected. The PRISMA flowchart is shown in Fig. 1.

Studies were excluded if MMC patients were a subset of the study. Studies were included and critically evaluated if they fell into 1 of the following categories: 1) MMC closure technique and hydrocephalus rate; 2) hydrocephalus treatment modality; and 3) timing of hydrocephalus treatment. Relevant information from papers was extracted.

\section{Results \\ NIS Cohort Characteristics}

Table 1 displays the NIS cohort characteristics stratified 
PRISMA 2009 Flow Diagram

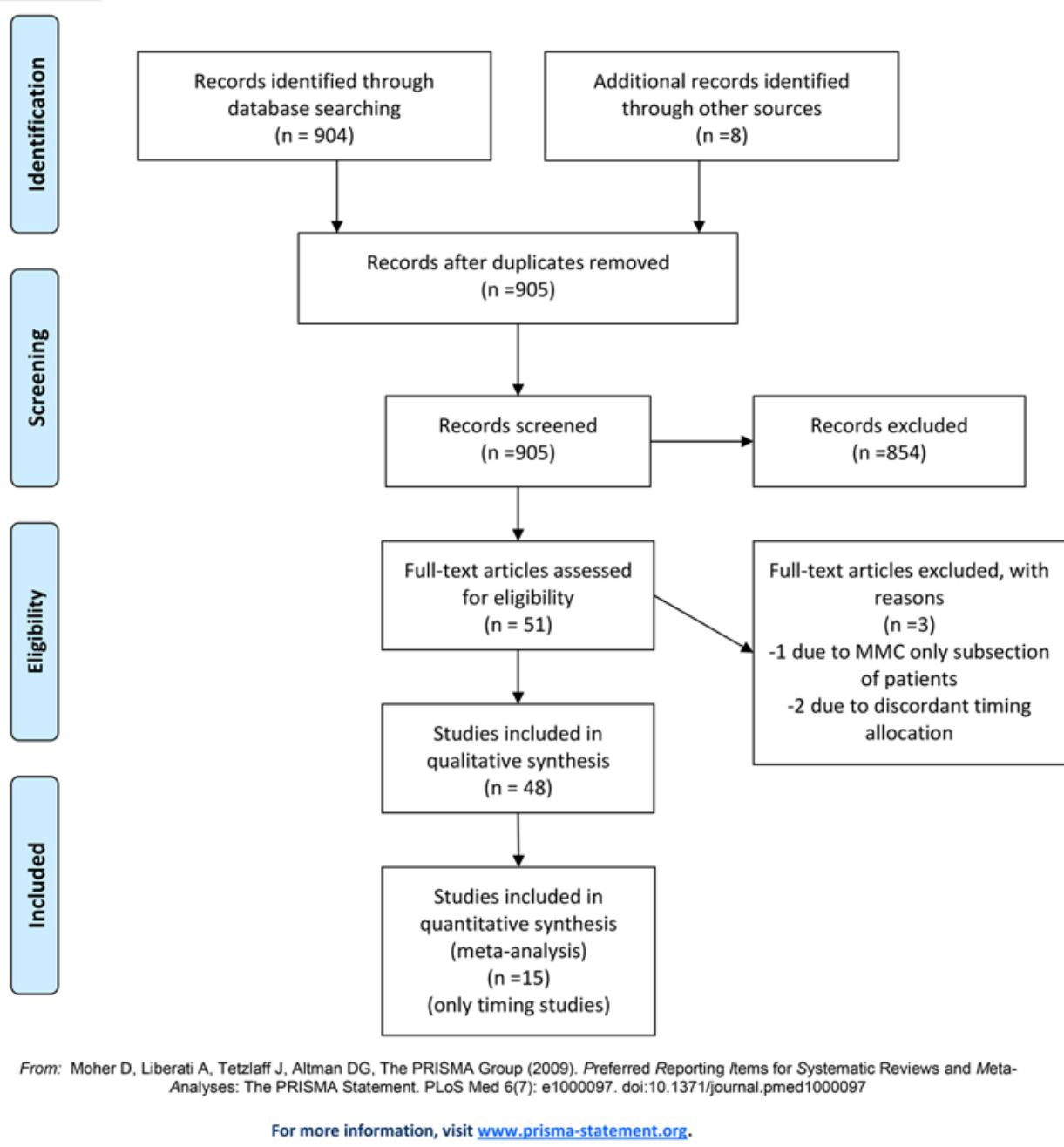

FIG. 1. PRISMA flowchart of systematic review. Data added to the PRISMA template (from Moher D, Liberati A, Tetzlaff J, Altman DG, The PRISMA Group [2009]. Preferred Reporting Items for Systematic Reviews and Meta-Analyses: The PRISMA Statement. PLoS Med 6(7):e1000097) under the terms of the Creative Commons Attribution License.

by hydrocephalic status. From 1998 to 2014, a weighted total of 10,627 inpatient MMC repairs were documented in the NIS, 8233 (77.5\%) of which had documented hydrocephalus. Patient race $(\mathrm{p}=0.0051)$ and patient insurance status $(\mathrm{p}=0.0004)$ had a significant effect on hydrocephalus rates; white or Hispanic and Medicaid patients were most likely to be diagnosed with hydrocephalus. Level of MMC did not significantly affect hydrocephalus status and the number of patients coded for MMC with hydrocephalus versus without hydrocephalus did not change over time. Patients with hydrocephalus had longer median length of inpatient stay compared to those without the diagnosis.

\section{NIS Hydrocephalus Treatment}

Of the 8233 patients with MMC and hydrocephalus, $5876(71.4 \%)$ were treated with VPS, $331(4.0 \%)$ were treated with ETV, and 2026 (24.6\%) received no hydrocephalus treatment on initial inpatient stay. Treatment modality rates were stable overtime (Fig. 2, early vs late period, $\mathrm{p}=0.2595$ ) and did not differ based on academic hospital status $(\mathrm{p}=0.5938)$, hospital region $(\mathrm{p}=0.5590)$, patient race $(\mathrm{p}=0.5175)$, or patient insurance status $(\mathrm{p}=$ 0.1667 ). When analyzing hydrocephalus treatment versus no treatment during inpatient stay using univariable logistic regression, patients in later years with hydrocephalus were less likely to receive hydrocephalus treatment during initial inpatient stay (odds ratio [OR] 0.974, 95\% confidence interval $[\mathrm{CI}] 0.951-0.998, \mathrm{p}=0.0331)$. However, this difference was not significant when analyzed using early versus late time periods $(76.9 \%$ vs $73.9 \%, \mathrm{p}=0.1644)$.

Of the 6208 patients who received treatment for hydrocephalus, the inpatient hydrocephalus treatment failure rate was significantly higher for patients who received 
TABLE 1. NIS cohort characteristics

\begin{tabular}{|c|c|c|c|c|}
\hline Characteristic & Overall $(n=10,627)$ & Hydrocephalic $(n=8233)$ & Nonhydrocephalic ( $n=2394$ ) & $\mathrm{p}$ Value \\
\hline Female & $5078(47.8)$ & $3965(48.2)$ & $1112(46.5)$ & 0.5132 \\
\hline Median length of stay (IQR), days & $11.9(11.3)$ & $13.3(12.1)$ & $7.9(6.6)$ & $<0.0001$ \\
\hline MMC level & & & & 0.5236 \\
\hline Lumbar & $9041(85.1)$ & $7037(85.5)$ & $2004(83.7)$ & \\
\hline Thoracic & $521(4.9)$ & $406(4.9)$ & $115(4.8)$ & \\
\hline Cervical & $61(0.6)$ & $39(0.5)$ & $22(0.9)$ & \\
\hline Unspecified & $1005(9.5)$ & $751(9.1)$ & $254(10.6)$ & \\
\hline Patient race & & & & 0.0051 \\
\hline White & $4256(56.6)$ & $3396(57.5)$ & $860(53.3)$ & \\
\hline African American & $718(9.6)$ & $551(9.3)$ & $167(10.3)$ & \\
\hline Hispanic & $1777(23.6)$ & $1440(24.4)$ & $337(20.9)$ & \\
\hline Asian or Pacific Islander & $118(1.6)$ & $78(1.3)$ & $40(2.5)$ & \\
\hline Zip code income quartile, $\$$ & & & & 0.0886 \\
\hline $1-24,999$ & $2827(27.2)$ & $2284(28.3)$ & $543(23.1)$ & \\
\hline $25,000-34,999$ & $2852(27.4)$ & $2214(27.5)$ & $638(27.2)$ & \\
\hline $35,000-44,999$ & $2711(26.0)$ & $2074(25.7)$ & $636(27.1)$ & \\
\hline 45,000 or more & $2022(19.4)$ & $1491(18.5)$ & $531(22.6)$ & \\
\hline Insurance status & & & & 0.0004 \\
\hline Medicaid & $5413(51.2)$ & $4373(53.3)$ & $1040(43.5)$ & \\
\hline Private insurance & 4369 (41.2) & $3189(38.8)$ & $1180(49.4)$ & \\
\hline Self-pay & $315(3.0)$ & $247(3.0)$ & $68(2.9)$ & \\
\hline Hospital region & & & & 0.3039 \\
\hline Northeast & 1406 (13.2) & $1044(12.7)$ & $362(15.1)$ & \\
\hline Midwest & $3242(30.5)$ & 2595 (31.5) & $646(27.0)$ & \\
\hline South & $3093(29.1)$ & $2358(28.6)$ & $735(30.7)$ & \\
\hline West & $2886(27.2)$ & $2236(27.2)$ & $650(27.2)$ & \\
\hline Academic hospital status & $9739(92.6)$ & $7506(92.2)$ & $2233(93.8)$ & 0.2394 \\
\hline Hospital bed size & & & & 0.6990 \\
\hline Small & $1457(13.8)$ & $1094(13.4)$ & $363(15.3)$ & \\
\hline Medium & $2053(19.5)$ & 1593 (19.5) & $460(19.3)$ & \\
\hline Large & $7028(66.7)$ & $5472(67.1)$ & $1557(65.4)$ & \\
\hline
\end{tabular}

Weighted frequencies and column percentiles displayed unless otherwise stated. Some variables may be missing data from a few patients.

ETV (17.5\% ETV failure rate vs $7.9 \%$ VPS failure rate; $\mathrm{p}=0.0028)$.

\section{NIS Timing of Hydrocephalus Treatment}

Only 4551 of the patients treated for hydrocephalus had day-of-procedure information available for both MMC and hydrocephalus treatment. Treatment information stratified by time of treatment, ST versus DT, is displayed in Table 2. DT was more prevalent in the later time period (DT-late $77.9 \%$ vs DT-early $69.5 \%, \mathrm{p}=0.0287$ ). This time trend is shown in Fig. 3. This trend was also significant when analyzed with a more accurate univariable yearly logistic regression (OR 1.06, 95\% CI 1.019-1.102, p = 0.0039). DT was also more prevalent in patients with zip codes from poorer neighborhoods $(\mathrm{p}=0.0139)$, and in medium-sized hospitals $(p=0.0292)$. The median number of days delayed before hydrocephalus treatment was 7 (IQR 7; distribution shown in Fig. 3).
Of the 4285 patients who received first treatment with VPS with procedure day available, 115 (2.7\%) had documented shunt infection during initial inpatient stay. There was no significant difference in shunt infection rate and time of shunt placement (ST 1.3\% vs DT 3.1\%, p $=0.1373$ ). Compared to patients with ST, those with DT were more likely to have shunt failure during the inpatient stay $(10.4 \%$ DT failure vs $1.9 \%$ ST failure, $p=0.0002$ ). In the univariable analysis we identified length of stay, shunt infection, jaundice, tachycardia, hematological diagnosis, respiratory distress, zip code income, and delayed treatment as correlating factors of inpatient shunt failure. However, the only significant independent correlating factors were length of stay, shunt infection, jaundice, and delayed treatment (Table 3). When days between hydrocephalus treatment and MMC repair was analyzed as a continuous variable, a longer duration between operations increased the likelihood of inpatient shunt failure (OR 1.10, p < 0.0001). 


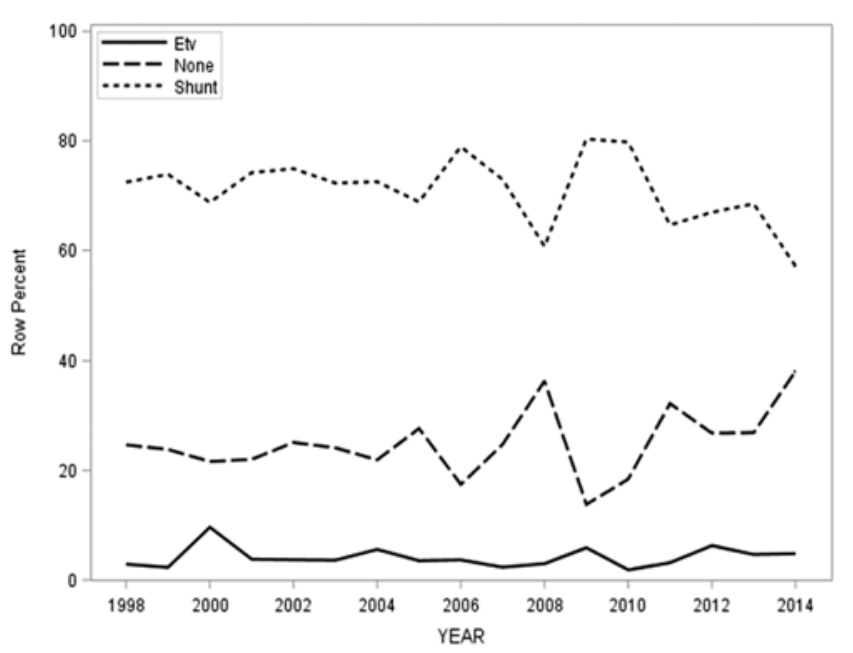

FIG. 2. Trend of treatment modalities for MMC-related hydrocephalus from 1998 to 2014.

There was no difference in ETV failure with regard to treatment time, although this was likely influenced by the low number of patients (ST 12.2\% vs DT 21.4\%; $\mathrm{p}=$ $0.4388)$.

\section{Systematic Review}

The systematic review identified 905 articles; 8 articles were from additional sources. A total of 48 articles met the inclusion criteria: 17 discussed hydrocephalus rates with regard to MMC closure technique, $1,5-7,13,14,19-21,26,37,45,51$, 56-58,67 16 involved MMC-associated hydrocephalus treatment modality and outcomes, $, 3,4,9,22,24,28,36,39,42,46,50,53-55,61,62$ and 15 the timing of hydrocephalus treatment. . $^{2,9,10,15,18,25 \text {, }}$ $29-31,35,41,44,49,60,66$

\section{Discussion}

\section{Rates of Hydrocephalus Following Different MMC Closure Techniques}

Among the complications associated with MMCs, hydrocephalus is one of the most common and debilitating. Prior to the advent of CSF shunting, most hydrocephalic MMC patients did not survive beyond 2 years of age..$^{14,47}$ Following the introduction of CSF shunts in the 1950s, many advocated for the indiscriminate, aggressive treatment of hydrocephalus in MMC patients, which resulted in a significant proportion receiving VPS at the same time as their postnatal MMC repair. ${ }^{6,47}$ Since then, many studies have evaluated the need for surgical intervention of MMC-related hydrocephalus following postnatal closure of MMC, with reported VPS rates ranging from $57 \%$ to $86 \%$. The majority of patients with shunts placed ultimately require at least 1 VPS revision during their lifetime. . $^{6,14,19,26,37,48,59,63,65}$

In 1998, the first human intrauterine MMC closure was reported and the following year the first prospective human study evaluating intrauterine repair of MMC was published.,56 Their findings were the foundation for the MOMS trial, which concluded that prenatal closure of
MMCs resulted in significantly lower rates of postnatal hydrocephalus, with a reported prenatal repair VPS rate of $40 \%$ versus a postnatal repair rate of $82 \%$. Fewer motor deficits were also observed at 30 months postdelivery ( $\mathrm{p}=$ 0.007). However, these patients did exhibit higher rates of preterm delivery and uterine dehiscence when compared to the postnatal surgery group. ${ }^{1}$

In 2016, the single-arm CECAM study demonstrated that using prenatal fetoscopic techniques resulted in similar rates of postnatal CSF diversion procedures (approximately $42 \%$ ) with a lower likelihood of uterine dehiscence compared to the open technique used in MOMS; however, preterm delivery rates were no different. ${ }^{45}$

Using rigorous criteria for VPS placement, which included tolerating some ventricular dilation in the absence of clinical findings, Chakraborty et al. demonstrated that rates of VPS placement following postnatal repair (51.9\%) were close to those seen in MOMS and CECAM. However, these results were retrospective in nature and did not evaluate neurological function as an outcome measure. ${ }^{11,40}$

\section{Treatment of MMC-Associated Hydrocephalus}

\section{Ventricular Shunting}

The standard surgical treatment for MMC-associated hydrocephalus is ventricular CSF shunt drainage, typically to the peritoneal cavity (VPS). However, shunts carry a risk of infection and malfunction that often necessitate revisions. In 1985, Liptak et al. evaluated 67 children with neural tube defects treated with VPS and found that $30 \%$ required at least 1 shunt revision and $22 \%$ required multiple revisions. ${ }^{28}$ Additional investigations report shunt malfunction rates ranging from $14.7 \%$ to $64 \%$ and shunt infection rates ranging from $2.9 \%$ to $15.3 \%$. $3,9,55$

Studies have attempted to assess potential risk factors predisposing to shunt malfunction. Caldarelli et al. explored shunt complications over the first postoperative year in 170 children. ${ }^{9}$ They demonstrated that thoracic and cervical MMCs treated with VPS were more likely to have VPS complications, whereas age and surgical modality did not significantly influence shunt patency or overall complications. In the long-term follow up of 189 hydrocephalic MMC patients, Tuli et al. observed a $64 \%$ first-shunt failure rate due to obstruction (70\%), infection (24\%), or loculated ventricles $(4 \%) .{ }^{55}$ On multivariate analysis, these investigators found female sex and concurrent surgical procedure (including nonneurosurgical procedures) had a significant increase in subsequent shunt malfunction. Our NIS failed to find sex or MMC level associated with inpatient failure rates, likely due to our ability to only capture events during initial inpatient stay. However, we did identify surgical timing and specific comorbidities as correlates to higher risk of inpatient VPS failure.

With high rates of revision due to shunt-related complications, there has been effort directed toward optimization of shunt selection. In a retrospective review of 157 patients with neonatal MMC, patients were classified according to shunt system features, including valve type, valve size/ contour, and catheter type. A total of 71 patients (45.2\%) underwent early shunt revision due to various complications and there was no association between complica- 
TABLE 2. Hydrocephalus treatment timing

\begin{tabular}{|c|c|c|c|c|}
\hline Characteristic & Overall $(n=4551)$ & ST $(n=1167)$ & DT $(n=3383)$ & $\mathrm{p}$ Value \\
\hline Female & $2176(47.8)$ & $569(48.7)$ & $1607(47.5)$ & 0.7569 \\
\hline Median length of stay (IQR), days & $14.7(13.5)$ & $11.6(12.6)$ & $15.6(13.6)$ & 0.0001 \\
\hline Shunt infection* & $115(2.7)$ & $14(1.3)$ & $101(3.1)$ & 0.1373 \\
\hline Inpatient shunt revision* & $353(8.2)$ & $20(1.9)$ & $333(10.4)$ & 0.0002 \\
\hline Time period & & & & 0.0287 \\
\hline Early (1998-2006) & $1941(42.7)$ & $592(30.5)$ & $1349(69.5)$ & \\
\hline Late (2007-2014) & $2610(57.3)$ & $575(22.1)$ & $2034(77.9)$ & \\
\hline First Tx & & & & 0.2700 \\
\hline ETV & $265(5.8)$ & $87(32.8)$ & $178(67.2)$ & \\
\hline Shunt & $4285(94.2)$ & $1080(25.2)$ & $3205(74.8)$ & \\
\hline Patient race $†$ & & & & 0.9061 \\
\hline White & $1974(60.6)$ & $493(59.2)$ & $1481(61.1)$ & \\
\hline African American & $374(11.5)$ & $94(11.3)$ & $279(11.5)$ & \\
\hline Hispanic & $909(27.9)$ & $245(29.4)$ & $66(27.4)$ & \\
\hline Zip code income quartile, \$ & & & & 0.0139 \\
\hline $1-24,999$ & $1301(29.3)$ & $249(19.1)$ & $1052(80.9)$ & \\
\hline $25,000-34,999$ & $1230(27.7)$ & $300(24.4)$ & $930(75.6)$ & \\
\hline $35,000-44,999$ & $1143(25.7)$ & $342(29.9)$ & $801(70.1)$ & \\
\hline 45,000 or more & $768(17.3)$ & $240(31.2)$ & $528(68.8)$ & \\
\hline Insurance status $†$ & & & & 0.7104 \\
\hline Medicaid & $2413(57.1)$ & $623(56.2)$ & $1790(57.4)$ & \\
\hline Private insurance & $1469(34.7)$ & $414(37.4)$ & $1055(33.8)$ & \\
\hline Hospital region & & & & 0.8160 \\
\hline Northeast & $792(17.4)$ & $172(21.8)$ & $620(78.2)$ & \\
\hline Midwest & $1001(22.0)$ & $253(21.7)$ & $747(74.7)$ & \\
\hline South & $1423(31.3)$ & $367(25.8)$ & $1056(74.2)$ & \\
\hline West & $1335(29.3)$ & $375(28.1)$ & $960(71.9)$ & \\
\hline Academic hospital status & $4196(93.3)$ & $1034(91.3)$ & $3162(94.0)$ & 0.3146 \\
\hline Hospital bed size & & & & 0.0292 \\
\hline Small & $693(15.4)$ & $193(17.0)$ & $500(14.9)$ & \\
\hline Medium & $742(16.5)$ & $103(9.1)$ & $639(19.0)$ & \\
\hline Large & 3062 (68.1) & 837 (73.9) & $2224(66.1)$ & \\
\hline
\end{tabular}

tions and valve type or catheter type, although small-sized valves demonstrated significantly lower rates of wound complications. ${ }^{24}$

\section{ETV}

ETV is an alternative method of hydrocephalus treatment and avoids many common infection and mechanical pitfalls associated with shunting. The first small series we identified that incorporated ETVs in MMC patients was documented in 1981 by Natelson. In a series of 20 neonatal hydrocephalic MMC patients, 9 received a shunt with ETV and 11 received a shunt alone. ${ }^{39}$ No revisions were needed in the shunt-ETV group, but $54 \%$ of patients treated with a shunt alone required subsequent revision.
While Natelson demonstrated the feasibility of adjunct ETV treatment for MMC hydrocephalus, it was not until 1996 when the first large series of ETVs utilized as a singular treatment for hydrocephalus was published. In 64 patients with hydrocephalic MMC, Teo and Jones reported an overall ETV success rate of $72 \%$, with a significant difference in success rate of infants younger than 6 months of age (12.5\% success rate) compared to those over 6 months of age (80\% success rate).$^{54}$ Rei et al. also observed an ETV success rate that correlated directly with older patient age. Importantly, a prior VPS malfunction or infection did not contraindicate ETV. ${ }^{50}$ Our NIS results agree with the reported high rate of early-age ETV failure rates, with a $17.5 \%$ inpatient ETV failure rate. From 

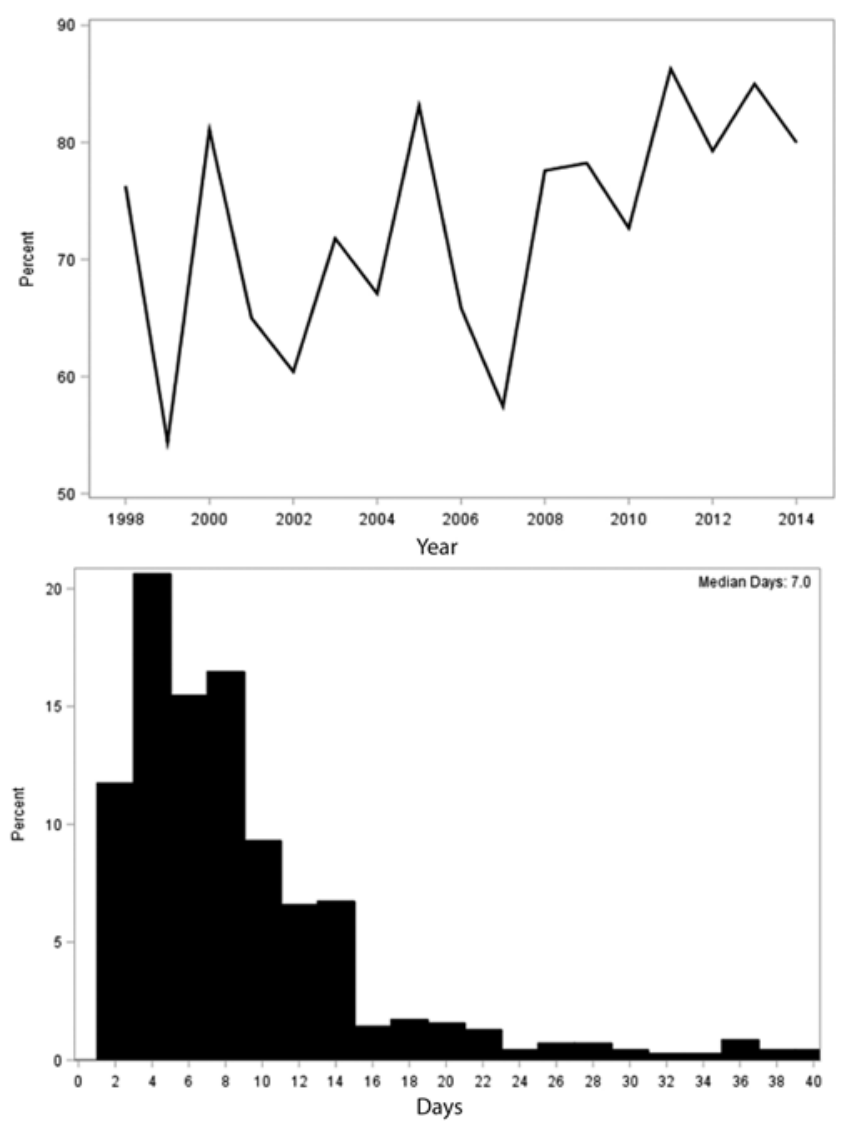

FIG. 3. Timing of treatment for MMC-related hydrocephalus. Upper: Trend of delayed inpatient hydrocephalus treatment (DT) over time. Lower: Histogram of days following MMC closure until hydrocephalus treatment among those patients who were delayed.

papers we identified, the reported success rates for ETV as a primary treatment ranged from $29 \%$ to $37.5 \%$, whereas success rates for ETV after shunt failure ranged from $50 \%$ to $92 \%{ }^{22,46,50,54}$ Long-term ETV outcomes after 5 years follow-up demonstrated ETV success rates of $53.3 \%$ and $64.3 \%$ when used as a first or second treatment modality, respectively.$^{53}$ Long-term neurocognitive outcomes between ETV and VPS groups are similar. ${ }^{53}$

In 2008, Warf and Campbell evaluated ETV with CPC of both lateral ventricles, aiming to reduce CSF production. ${ }^{62}$ In 93 patients with MMC who received ETV-CPC, the procedure demonstrated a success rate of $76 \%$ with no need for additional surgery (mean follow-up 19 months). Multivariable analysis showed that scarring of the choroid plexus $(\mathrm{p}=0.026)$ or of the cisterns $(\mathrm{p}=0.021)$ resulted in a higher failure rate, but age was not a significant predictor. In a later study, Warf et al. compared neurocognitive outcomes in MMC patients, including 55 treated with ETV-CPC, 19 with VPSs, and 19 who received no treatment. The ETV-CPC and VPS groups were similar except in receptive communication, which was better in the ETVCPC group. ${ }^{61}$

Comparing different hydrocephalus treatment modalities, Beuriat et al. evaluated 70 patients with MMC: 32 with ETV-CPC, 20 with ETV-VPS, and 18 with VPS alone. ${ }^{4}$ Failure rates were $28 \%$ in the ETV-CPC group, $35 \%$ in the ETV-VPS group, and 50\% with VPS alone (mean follow-up 8.5 years). Causes of failure in the ETVCPC group were due to insufficient drainage, with 3 cases found to have a closed stoma and 6 cases found to have an enlarged stoma.

Although ETV offers an alternative to conventional VPS treatment, use of this treatment varies across centers. MMC characteristics such as dysplastic ventricular anomalies, increased ventricular floor thickness, huge massa intermedia, narrow foramen of Monro, or a narrow prepontine cistern with posterior fossa crowding are all cited characteristics that interfere with treatment success. ${ }^{4,36}$ In our NIS data we hypothesized that ETV treatment would increase over the time period as this has been noted at individual centers, ${ }^{12,64}$ but there was no change in ETV treatment over time when analyzed. It is possible that even though some centers have embraced an increase in ETV, these trends are lost when assessing the national

TABLE 3. Univariable and multivariable logistic regression of inpatient shunt failure

\begin{tabular}{|c|c|c|c|c|c|c|}
\hline \multirow[b]{2}{*}{ Variable } & \multicolumn{3}{|c|}{ Univariable } & \multicolumn{3}{|c|}{ Multivariable } \\
\hline & OR & $95 \% \mathrm{Cl}$ & $\mathrm{p}$ Value & OR & $95 \% \mathrm{Cl}$ & $p$ Value \\
\hline Length of stay & 1.02 & $1.01-1.03$ & 0.0002 & 1.02 & $1.0-1.0$ & 0.0029 \\
\hline Shunt infection & 23.0 & $8.5-62.4$ & $<0.0001$ & 15.4 & $5.3-45.0$ & $<0.0001$ \\
\hline Jaundice & 3.6 & $1.8-7.0$ & 0.0002 & 2.9 & $1.5-5.8$ & 0.0022 \\
\hline Tachycardia & 3.9 & $0.9-15.7$ & 0.0508 & 3.0 & $0.9-10.4$ & 0.0834 \\
\hline Hematological diagnosis & 3.1 & $1.6-6.2$ & 0.0014 & - & - & - \\
\hline Respiratory distress & 4.4 & $2.1-9.3$ & 0.0001 & - & - & - \\
\hline Zip code income, $\$^{*}$ & & & & - & - & - \\
\hline $25,000-34,999$ & 1.7 & $0.9-3.3$ & 0.1100 & - & - & - \\
\hline $35,000-44,999$ & 1.1 & $0.5-2.3$ & 0.7763 & - & - & - \\
\hline 45,000 or more & 0.6 & $0.3-1.5$ & 0.3167 & - & - & - \\
\hline Same-day hydrocephalus Tx & 0.2 & $0.1-0.5$ & 0.0010 & 0.2 & $0.1-0.7$ & 0.0076 \\
\hline
\end{tabular}

* Reference: \$1-\$24,999. 
TABLE 4. Identified studies investigating time of MMC hydrocephalus treatment and complications

\begin{tabular}{|c|c|c|c|c|c|c|c|c|c|c|}
\hline \multirow[b]{3}{*}{ Authors \& Year } & \multirow{2}{*}{\multicolumn{2}{|c|}{ Patients }} & \multirow{2}{*}{\multicolumn{2}{|c|}{ Shunt Revisions }} & \multicolumn{6}{|c|}{ Infection } \\
\hline & & & & & \multicolumn{2}{|c|}{ Overall } & \multicolumn{2}{|c|}{ Shunt } & \multicolumn{2}{|c|}{ Wound } \\
\hline & DT & ST & DT & ST & DT & ST & DT & ST & DT & ST \\
\hline Khattak et al., 2018 & 49 & 49 & - & - & 10 & 6 & - & - & - & - \\
\hline Arslan et al., 2011 & 29 & 65 & - & - & 1 & 8 & 1 & 8 & - & - \\
\hline Yilmaz et al., 2010 & 27 & 38 & - & - & 5 & 4 & - & - & - & - \\
\hline Margaron et al., 2010 & 245 & 31 & 34 & 8 & 50 & 16 & 16 & 8 & 34 & 8 \\
\hline Wakhlu et al., 2009 & 135 & 110 & - & - & 5 & 0 & 2 & 0 & 3 & 0 \\
\hline Radmanesh et al., 2009 & 65 & 46 & 15 & 8 & 8 & 5 & 8 & 5 & - & - \\
\hline Oktem et al., 2008 & 63 & 31 & - & - & 14 & 16 & 9 & 6 & 5 & 7 \\
\hline Machado et al., 2004 & 7 & 11 & 0 & 3 & 1 & 2 & 0 & 1 & 1 & 1 \\
\hline Miller et al., 1996 & 48 & 21 & 4 & 4 & 2 & 1 & 2 & 1 & - & - \\
\hline Chadduck \& Reding, 1988 & 11 & 22 & 2 & 3 & 1 & 1 & 1 & 1 & - & - \\
\hline Hubballah \& Hoffman, 1987 & 0 & 10 & - & - & - & 0 & - & 0 & - & 0 \\
\hline Epstein et al., 1985 & 6 & 6 & 4 & 1 & 2 & 2 & - & - & 2 & 2 \\
\hline McDowell et al., 2018 & 31 & 14 & 15 & 5 & 12 & 2 & 4 & 2 & 8 & 0 \\
\hline Caldarelli et al., 1996 & 138 & 26 & 65 & 8 & 10 & 6 & 10 & 6 & - & - \\
\hline Totals & 854 & 480 & $\begin{array}{l}139 / 551 \\
(25.2 \%)\end{array}$ & $\begin{array}{c}40 / 177 \\
(22.6 \%)\end{array}$ & $\begin{array}{l}121 / 854 \\
(14.2 \%)\end{array}$ & $\begin{array}{l}69 / 480 \\
(14.4 \%)\end{array}$ & $\begin{array}{l}53 / 772 \\
(6.9 \%)\end{array}$ & $\begin{array}{l}38 / 387 \\
(9.8 \%)\end{array}$ & $\begin{array}{l}53 / 487 \\
(10.9 \%)\end{array}$ & $\begin{array}{l}18 / 213 \\
(8.4 \%)\end{array}$ \\
\hline p Value & & & \multicolumn{2}{|c|}{0.5805} & \multicolumn{2}{|c|}{0.9286} & \multicolumn{2}{|c|}{0.1047} & \multicolumn{2}{|c|}{0.3736} \\
\hline
\end{tabular}

trends, as many other centers have not adopted ETV. We observed no difference in treatment modalities between centers when stratified by size, academic status, or region. The NIS cannot select specifically for children's hospitals with pediatric neurosurgeons, so it is possible trends at smaller numbers of centers may be obscured by the overall population. Regardless, we can conclude based on NIS data that, nationally, patients treated over the time period had a stable rate of ETV.

\section{Time of Hydrocephalus Treatment}

After the initial introduction of VPS for MMC-associated hydrocephalus, many practitioners began repairing MMCs and placing shunts in patients simultaneously. ${ }^{6,47}$ Since the initial paper by Epstein et al. in 1985, numerous studies have been conducted that compare DT to ST with regard to shunt malfunction rate and MMC wound infection rate. ${ }^{15}$ Many surgeons delay shunting to ensure CSF sterility prior to VPS; however, in our NIS analysis there was no difference in infection rate between ST and DT. We observed that inpatient treatment timing for hydrocephalus became increasingly delayed between 1998 and 2014. Furthermore, the number of MMC patients diagnosed with hydrocephalus who were discharged without treatment increased over the time period. Together, these findings suggest that some patients in early years who were treated with ST may never have required hydrocephalus treatment on the initial inpatient stay if DT criteria were utilized. Unfortunately, the NIS is limited to initial stay, so we were unable to determine which patients discharged without hydrocephalus treatment ultimately underwent surgery versus those with no intervention.
Table 4 displays identified hydrocephalus treatment timing studies and their associated shunt malfunction and infection rates. A few studies did not distinguish VPS infection from wound infection, therefore an overall infection count is presented as well. A total of $1434 \mathrm{MMC}$ patients were identified, 854 patients underwent DT and 480 ST. The aggregate rates of shunt malfunction, overall infection, VPS infection, and wound infection did not significantly differ between the two treatment times. These aggregate conclusions agree with the majority of the single-paper conclusions. Interestingly, our NIS data somewhat contradict these aggregate conclusions, with DT patients demonstrating a higher likelihood of inpatient shunt failure, defined as return to the operating room for hydrocephalus. When days between operations was analyzed separately, each additional day between operations increased failure likelihood by $10 \%$. The majority of the identified studies followed the patients for a long period of time, whereas our NIS data are limited to the initial inpatient follow up. We do not hypothesize that our results suggest ST superiority, as we cannot assess more longterm failure, and some patients may be able to avoid shunt placement altogether. Our data do suggest that in those patients undergoing shunt insertion during their initial hospital stay, DT patients may experience earlier shunt failures compared to those who receive ST.

Many of the identified studies investigating timing of treatment are from countries other than America and cite a socioeconomically challenged population, in which ST is preferred due to its lower economic burden. ${ }^{49,60}$ As one may expect, the wealthier patients in the NIS comprised a smaller portion of MMC patients and had a lower incidence of associated hydrocephalus. Unexpectedly, when 
treated, wealthier NIS-MMC hydrocephalic patients were more likely to receive ST treatment.

\section{Strengths and Limitations}

Our study draws strength from its utilization of a large nationwide survey consisting of a stratified-clustered sample from many insurers intended to accurately represent the annual US inpatient population. However, the hospital sampling is not biased on available subspecialties within each institution, and hydrocephalus management may vary drastically from institution to institution. Care at academic children's centers with pediatric neurosurgery may be different than at hospitals with less specialized care, and specific hospital trends may be diluted among overall treatment trends nationwide. The NIS data also precludes incorporation of prenatal management of MMC. The NIS does not include information on MMC severity, intention to treat, and imaging. NIS analyses are limited to inpatient data and are therefore unable to assess long-term results. Additionally, the NIS analysis relies on accurate ICD-9 coding, which is error-prone.

\section{Conclusions}

The management of MMC-associated hydrocephalus has evolved over time. In the US from 1998 to 2014, hydrocephalus treatment has become more delayed and the number of patients with hydrocephalic MMC not treated on initial inpatient stay has increased. Our NIS analysis suggests that delayed treatment of hydrocephalus during initial hospitalization resulted in a higher likelihood of inpatient shunt failure. However, a meta-analysis that incorporates longer follow-up demonstrated that shunt malfunction and infection rates do not differ between delayed and simultaneous hydrocephalus treatment.

\section{References}

1. Adzick NS, Thom EA, Spong CY, Brock JW III, Burrows PK, Johnson MP, et al: A randomized trial of prenatal versus postnatal repair of myelomeningocele. N Engl J Med 364:993-1004, 2011

2. Arslan M, Eseoglu M, Gudu BO, Demir I, Kozan A, Gokalp A, et al: Comparison of simultaneous shunting to delayed shunting in infants with myelomeningocele in terms of shunt infection rate. Turk Neurosurg 21:397-402, 2011

3. Bell WO, Arbit E, Fraser RA: One-stage meningomyelocele closure and ventriculoperitoneal shunt placement. Surg Neurol 27:233-236, 1987

4. Beuriat PA, Szathmari A, Grassiot B, Plaisant F, Rousselle C, Mottolese C: Role of endoscopic third ventriculostomy in the management of myelomeningocele-related hydrocephalus: a retrospective study in a single French institution. World Neurosurg 87:484-493, 2016

5. Botelho RD, Imada V, Rodrigues da Costa KJ, Watanabe LC, Rossi Júnior R, De Salles AAF, et al: Fetal myelomeningocele repair through a mini-hysterotomy. Fetal Diagn Ther 42:28-34, 2017

6. Bowman RM, McLone DG, Grant JA, Tomita T, Ito JA: Spina bifida outcome: a 25-year prospective. Pediatr Neurosurg 34:114-120, 2001

7. Bruner JP, Tulipan N, Paschall RL, Boehm FH, Walsh WF, Silva SR, et al: Fetal surgery for myelomeningocele and the incidence of shunt-dependent hydrocephalus. JAMA 282:1819-1825, 1999
8. Burmeister R, Hannay HJ, Copeland K, Fletcher JM, Boudousquie A, Dennis M: Attention problems and executive functions in children with spina bifida and hydrocephalus. Child Neuropsychol 11:265-283, 2005

9. Caldarelli M, Di Rocco C, La Marca F: Shunt complications in the first postoperative year in children with meningomyelocele. Childs Nerv Syst 12:748-754, 1996

10. Chadduck WM, Reding DL: Experience with simultaneous ventriculo-peritoneal shunt placement and myelomeningocele repair. J Pediatr Surg 23:913-916, 1988

11. Chakraborty A, Crimmins D, Hayward R, Thompson D: Toward reducing shunt placement rates in patients with myelomeningocele. J Neurosurg Pediatr 1:361-365, 2008

12. Dewan MC, Naftel RP: The global rise of endoscopic third ventriculostomy with choroid plexus cauterization in pediatric hydrocephalus. Pediatr Neurosurg 52:401-408, 2017

13. Elbabaa SK, Gildehaus AM, Pierson MJ, Albers JA, Vlastos EJ: First 60 fetal in-utero myelomeningocele repairs at Saint Louis Fetal Care Institute in the post-MOMS trial era: hydrocephalus treatment outcomes (endoscopic third ventriculostomy versus ventriculo-peritoneal shunt). Childs Nerv Syst 33:1157-1168, 2017

14. Elgamal EA: Natural history of hydrocephalus in children with spinal open neural tube defect. Surg Neurol Int 3:112, 2012

15. Epstein NE, Rosenthal AD, Zito J, Osipoff M: Shunt placement and myelomeningocele repair: simultaneous vs sequential shunting. Review of 12 cases. Childs Nerv Syst 1:145-147, 1985

16. Heffez DS, Aryanpur J, Hutchins GM, Freeman JM: The paralysis associated with myelomeningocele: clinical and experimental data implicating a preventable spinal cord injury. Neurosurgery 26:987-992, 1990

17. Heffez DS, Aryanpur J, Rotellini NA, Hutchins GM, Freeman JM: Intrauterine repair of experimental surgically created dysraphism. Neurosurgery 32:1005-1010, 1993

18. Hubballah MY, Hoffman HJ: Early repair of myelomeningocele and simultaneous insertion of ventriculoperitoneal shunt: technique and results. Neurosurgery 20:21-23, 1987

19. Januschek E, Röhrig A, Kunze S, Fremerey C, Wiebe B, Messing-Jünger M: Myelomeningocele - a single institute analysis of the years 2007 to 2015. Childs Nerv Syst 32:1281-1287, 2016

20. Johnson MP, Gerdes M, Rintoul N, Pasquariello P, Melchionni J, Sutton LN, et al: Maternal-fetal surgery for myelomeningocele: neurodevelopmental outcomes at 2 years of age. Am J Obstet Gynecol 194:1145-1152, 2006

21. Johnson MP, Sutton LN, Rintoul N, Crombleholme TM, Flake AW, Howell LJ, et al: Fetal myelomeningocele repair: short-term clinical outcomes. Am J Obstet Gynecol 189:482-487, 2003

22. Jones RF, Kwok BC, Stening WA, Vonau M: Third ventriculostomy for hydrocephalus associated with spinal dysraphism: indications and contraindications. Eur J Pediatr Surg 6 (Suppl 1):5-6, 1996

23. Kabagambe SK, Jensen GW, Chen YJ, Vanover MA, Farmer DL: Fetal surgery for myelomeningocele: a systematic review and meta-analysis of outcomes in fetoscopic versus open repair. Fetal Diagn Ther 43:161-174, 2018

24. Kahilogullari G, Etus V, Guler TM, Karabagli H, Unlu A: Does shunt selection affect the rate of early shunt complications in neonatal myelomeningocele-associated hydrocephalus? A multi-center study. Turk Neurosurg 28:303-306, 2018

25. Khattak HA, Gul N, Khan SA, Muhammad G, Aurangzeb A, Khan I: Comparison of simultaneous versus delayed ventriculoperitoneal shunting in patients undergoing meningocoele repair in terms of infection. J Ayub Med Coll Abbottabad 30:520-523, 2018 
26. Laskay NMB, Arynchyna AA, McClugage SG III, Hopson B, Shannon C, Ditty B, et al: A comparison of the MOMS trial results to a contemporaneous, single-institution, postnatal closure cohort. Childs Nerv Syst 33:639-646, 2017

27. Liberati A, Altman DG, Tetzlaff J, Mulrow C, Gøtzsche PC, Ioannidis JP, et al: The PRISMA statement for reporting systematic reviews and meta-analyses of studies that evaluate health care interventions: explanation and elaboration. PLoS Med 6:e1000100, 2009

28. Liptak GS, Masiulis BS, McDonald JV: Ventricular shunt survival in children with neural tube defects. Acta Neurochir (Wien) 74:113-117, 1985

29. Machado HR, Santos de Oliveira R: Simultaneous repair of myelomeningocele and shunt insertion. Childs Nerv Syst 20:107-109, 2004

30. Margaron FC, Poenaru D, Bransford R, Albright AL: Timing of ventriculoperitoneal shunt insertion following spina bifida closure in Kenya. Childs Nerv Syst 26:1523-1528, 2010

31. McDowell MM, Lee PS, Foster KA, Greene S: The use of external ventricular drainage to reduce the frequency of wound complications in myelomeningocele closure. Pediatr Neurosurg 53:100-107, 2018

32. McLone DG, Knepper PA: The cause of Chiari II malformation: a unified theory. Pediatr Neurosci 15:1-12, 1989

33. Meuli M, Meuli-Simmen C, Yingling CD, Hutchins GM, Hoffman KM, Harrison MR, et al: Creation of myelomeningocele in utero: a model of functional damage from spinal cord exposure in fetal sheep. J Pediatr Surg 30:1028-1033, 1995

34. Michejda M: Intrauterine treatment of spina bifida: primate model. Z Kinderchir 39:259-261, 1984

35. Miller PD, Pollack IF, Pang D, Albright AL: Comparison of simultaneous versus delayed ventriculoperitoneal shunt insertion in children undergoing myelomeningocele repair. J Child Neurol 11:370-372, 1996

36. Mori H, Oi S, Nonaka Y, Tamogami R, Muroi A: Ventricular anatomy of hydrocephalus associated with myeloschisis and endoscopic third ventriculostomy. Childs Nerv Syst 24:717722,2008

37. Morota N, Ihara S: Postnatal ascent of the cerebellar tonsils in Chiari malformation Type II following surgical repair of myelomeningocele. J Neurosurg Pediatr 2:188-193, 2008

38. Natarajan S, Lipsitz SR, Fitzmaurice GM, Sinha D, Ibrahim JG, Haas J, et al: An extension of the Wilcoxon Rank-Sum test for complex sample survey data. J R Stat Soc Ser C Appl Stat 61:653-664, 2012

39. Natelson SE: Early third ventriculostomy in meningomyelocele infants - shunt independence? Childs Brain 8:321-325, 1981

40. Norkett W, McLone DG, Bowman R: Current management strategies of hydrocephalus in the child with open spina bifida. Top Spinal Cord Inj Rehabil 22:241-246, 2016

41. Oktem IS, Menkü A, Ozdemir A: When should ventriculoperitoneal shunt placement be performed in cases with myelomeningocele and hydrocephalus? Turk Neurosurg 18:387-391, 2008

42. Oliveira MF, Teixeira MJ, Norremose KA, Matushita H, Oliveira MDL, Shu EB, et al: Surgical technique of retrograde ventricle-sinus shunt is an option for the treatment of hydrocephalus in infants after surgical repair of myelomeningocele. Arq Neuropsiquiatr 73:1019-1025, 2015

43. Ouzzani M, Hammady H, Fedorowicz Z, Elmagarmid A: Rayyan - a web and mobile app for systematic reviews. Syst Rev 5:210, 2016

44. Parent AD, McMillan T: Contemporaneous shunting with repair of myelomeningocele. Pediatr Neurosurg 22:132-136, 1995

45. Pedreira DA, Zanon N, Nishikuni K, Moreira de Sá RA, Acacio GL, Chmait RH, et al: Endoscopic surgery for the antena- tal treatment of myelomeningocele: the CECAM trial. Am J Obstet Gynecol 214:111.e1-111.e11, 2016

46. Perez da Rosa S, Millward CP, Chiappa V, Martinez de Leon M, Ibáñez Botella G, Ros López B: Endoscopic third ventriculostomy in children with myelomeningocele: a case series. Pediatr Neurosurg 50:113-118, 2015

47. Piatt JH Jr: Treatment of myelomeningocele: a review of outcomes and continuing neurosurgical considerations among adults. J Neurosurg Pediatr 6:515-525, 2010

48. Radcliff E, Cassell CH, Laditka SB, Thibadeau JK, Correia $\mathrm{J}$, Grosse SD, et al: Factors associated with the timeliness of postnatal surgical repair of spina bifida. Childs Nerv Syst 32:1479-1487, 2016

49. Radmanesh F, Nejat F, El Khashab M, Ghodsi SM, Ardebili HE: Shunt complications in children with myelomeningocele: effect of timing of shunt placement. Clinical article. J Neurosurg Pediatr 3:516-520, 2009

50. Rei J, Pereira J, Reis C, Salvador S, Vaz R: endoscopic third ventriculostomy for the treatment of hydrocephalus in a pediatric population with myelomeningocele. World Neurosurg 105:163-169, 2017

51. Rintoul NE, Sutton LN, Hubbard AM, Cohen B, Melchionni J, Pasquariello PS, et al: A new look at myelomeningoceles: functional level, vertebral level, shunting, and the implications for fetal intervention. Pediatrics 109:409-413, 2002

52. Sahni M, Ohri A: Meningomyelocele, in StatPearls. Treasure Island, FL: StatPearls Publishing LLC, 2019 (https://www.ncbi.nlm.nih.gov/books/NBK536959/) [Accessed August 9, 2019]

53. Tamburrini G, Frassanito P, Iakovaki K, Pignotti F, Rendeli C, Murolo D, et al: Myelomeningocele: the management of the associated hydrocephalus. Childs Nerv Syst 29:15691579,2013

54. Teo C, Jones R: Management of hydrocephalus by endoscopic third ventriculostomy in patients with myelomeningocele. Pediatr Neurosurg 25:57-63, 1996

55. Tuli S, Drake J, Lamberti-Pasculli M: Long-term outcome of hydrocephalus management in myelomeningoceles. Childs Nerv Syst 19:286-291, 2003

56. Tulipan N, Bruner JP: Myelomeningocele repair in utero: a report of three cases. Pediatr Neurosurg 28:177-180, 1998

57. Tulipan N, Bruner JP, Hernanz-Schulman M, Lowe LH, Walsh WF, Nickolaus D, et al: Effect of intrauterine myelomeningocele repair on central nervous system structure and function. Pediatr Neurosurg 31:183-188, 1999

58. Tulipan N, Sutton LN, Bruner JP, Cohen BM, Johnson M, Adzick NS: The effect of intrauterine myelomeningocele repair on the incidence of shunt-dependent hydrocephalus. Pediatr Neurosurg 38:27-33, 2003

59. Vinck A, Maassen B, Mullaart R, Rotteveel J: Arnold-ChiariII malformation and cognitive functioning in spina bifida. $\mathbf{J}$ Neurol Neurosurg Psychiatry 77:1083-1086, 2006

60. Wakhlu A, Wakhlu G, Saxena S, Tandon RK: Single-stage treatment of spina bifida with hydrocephalus based on a prediction rule derived from preoperative cranial ultrasound. Pediatr Neurosurg 45:271-275, 2009

61. Warf B, Ondoma S, Kulkarni A, Donnelly R, Ampeire M, Akona J, et al: Neurocognitive outcome and ventricular volume in children with myelomeningocele treated for hydrocephalus in Uganda. J Neurosurg Pediatr 4:564-570, 2009

62. Warf BC, Campbell JW: Combined endoscopic third ventriculostomy and choroid plexus cauterization as primary treatment of hydrocephalus for infants with myelomeningocele: long-term results of a prospective intent-to-treat study in 115 East African infants. J Neurosurg Pediatr 2:310-316, 2008

63. Wiedenbauer G, Jansen-Osmann P: Spatial knowledge of children with spina bifida in a virtual large-scale space. Brain Cogn 62:120-127, 2006

64. Xu R, McCrea HJ, Hoffman CE, Souweidane MM, Green- 
field JP: The impact of endoscopic third ventriculostomy on shunt revision rate: a 14-year experience at a single institution. World Neurosurg 84:677-680.e1, 2015

65. Yeates KO, Loss N, Colvin AN, Enrile BG: Do children with myelomeningocele and hydrocephalus display nonverbal learning disabilities? An empirical approach to classification. J Int Neuropsychol Soc 9:653-662, 2003

66. Yilmaz A, Müslüman AM, Dalgic N, Cavuşoğlu H, Kanat A, Colak I, et al: Shunt insertion in newborns with myeloschisis/myelomenigocele and hydrocephalus. J Clin Neurosci 17:1493-1496, 2010

67. Zamłyński J, Olejek A, Koszutski T, Ziomek G, Horzelska E, Gajewska-Kucharek A, et al: Comparison of prenatal and postnatal treatments of spina bifida in Poland-a non-randomized, single-center study. J Matern Fetal Neonatal Med 27:1409-1417, 2014

\section{Disclosures}

The authors report no conflict of interest concerning the materials or methods used in this study or the findings specified in this paper.

\section{Author Contributions}

Conception and design: McCrea, McCarthy, Luther. Acquisition of data: McCarthy, Sheinberg, Luther. Analysis and interpretation of data: McCrea, McCarthy, Luther. Drafting the article: all authors. Critically revising the article: McCrea, McCarthy, Sheinberg. Reviewed submitted version of manuscript: all authors. Statistical analysis: McCarthy. Administrative/technical/material support: McCrea. Study supervision: McCrea, McCarthy.

\section{Correspondence}

Heather J. McCrea: University of Miami Miller School of Medicine, Miami,FL.hmccrea@med.miami.edu. 